\title{
Taguchi Analysis of surface roughness and delamination associated with various cemented carbide K10 end mills in milling of GFRP
}

\author{
P. Praveen Raj ${ }^{1, *}$ and A. Elaya Perumal ${ }^{2}$ \\ ${ }^{I}$ Department of Mechanical Engineering, Thanthai Periyar Govt. Institute of Technology, Bagayam, Vellore, Tamil Nadu, India - 632002. \\ ${ }^{2}$ Engineering Design Divisions, Department of Mechanical Engineering, College of Engineering Guindy, Anna University, Chennai, Tamil Nadu, \\ India - 632025 .
}

Received 12 January 2010; Accepted 16 March 2010

\begin{abstract}
This Paper presents a study of surface roughness, precision and delamination factor in use of Ti-Namite carbide K10 end mill, Solid carbide K10 end mill and Tipped Carbide K10 end mill. A plan of experiment based on Taguchi was established with prefixed cutting parameters and the machining was performed. An Surfcoder to examine the surface roughness and Infrared Thermography to examine the delamination of chopped Glass fiber-reinforced plastic (GFRP) laminates was used. Earlier works reports that cutting velocity and feed rate makes significant contribution to overall performance. But, the experimental results of this paper indicates that the depth of cut are recognised to make the most significant contribution to the overall performance as compared to cutting velocity and feed rate. The objective was to establish a correlation between cutting velocity, feed rate and depth of cut with surface roughness and delamination in a GFRP laminate. The correlation was obtained by multiple-variable linear regression using Minitab14 software.
\end{abstract}

Keywords: Milling, Taguchi Method, Ti-Namite carbide, GFRP.

\section{Introduction}

Glass Fibre Reinforced Plastics (GFRP) composite is considered to be an alternative to heavy exortic materials. It is widely used in a variety of applications from aircraft to machine tools due to their light weight, high modulus and specific strength. [1]

Generally GFRP composite are manufactured to near shape components. Achieving an acceptable surface quality with conventional methods of machining has been found to be extremely difficult due to an Isotropic and Heterogeneous nature of these materials. In order to extend the applications of GFRP, milling becomes essential for removal of excess material to produce a well defined and high quality surface. [2]

Milling composite material is significantly affected by the tendency of these materials to delaminate under the action of cutting force, feed force and depth force respectively. [3, 4] Surface roughness is a characteristic that could influence the dimensional precision, the performance of the mechanical pieces and production cost. For these reasons there has been a lot of Research and Development with the objective of optimizing cutting conditions to obtain a determined surface roughness. [5, 6]

In summary many Authors [7-11], when reporting on milling of composite materials have shown that the surface roughness and

*E-mail address: ppraj_tpgit@rediffmail.com

ISSN: 1791-2377 (C) 2010 Kavala Institute of Technology. All rights reserved. delamination factor is strongly dependent on cutting parameters, tool geometry and cutting forces.

J. Paulo Davim and Pedro Reis [12] investigated on milling of carbon fiber reinforced plastic using two flute and four flute cemented carbide (K10) end mills.

All the above works contributes to the practice of using cemented carbide tools, while the use of various carbide tools and the characterization of their machiniablity were rarely discussed in design experiments. This paper presents a prediction of surface roughness, precision and delmaination of Ti-Namite coated carbide k10 end mill, Solid carbide K10 end mill and tipped carbide K10 end mill.

\section{Experimental Procedure \\ 2.1 Materials, Tools and Experimental setup.}

The composite materials used in the tests is made of epoxy matrix (Araldite LY556) reinforced with chopped fiber glass using hardener (HT 972) was produced by Hand-lay up procedure with $5 \mathrm{~mm}$ thickness (5 lay-ups) having a fiber orientation of $0 / 90^{\circ}$.

The experiment have been carried out in the laminate plate using K10 end mills of Solid carbide, Tipped carbide and Ti-Na- 
mite coated carbide tools shown in the fig. 1, having a diameter of $10 \mathrm{~mm}$ with four flutes.

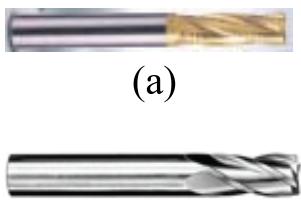

(b)

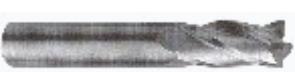

(c)

Figure 1. (a) Four-flute Ti-Nimate Coated (K10) end mill, (b) Four-flute solid carbide (K10) end mill, (c) Four-flute tipped (K10) end mill.

A Vertical machining centre with $10 \mathrm{kw}$ spindle power and a maximum spindle speed of $8000 \mathrm{rpm}$ was used to perform the experiments. The fixation of the composite material was made as shown in Fig 2, to make sure that vibration and displacements are eliminated.

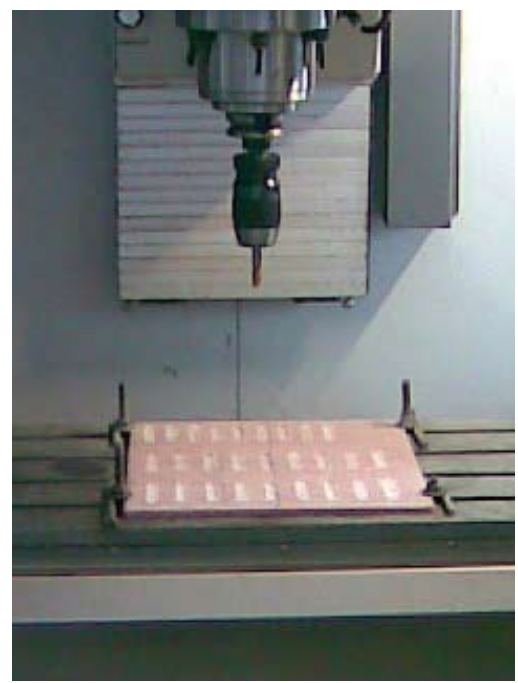

Figure 2. Fixation of the laminate plate in the table of Machining Centre.

\subsection{Measurements}

The surface roughness $\left(\mathrm{R}_{\mathrm{a}}\right)$ was evaluated using Surfcoder SE 1700 . The measurements were made with the cut-off $(0.8 \mathrm{~mm})$ according to ISO as shown in fig 3.

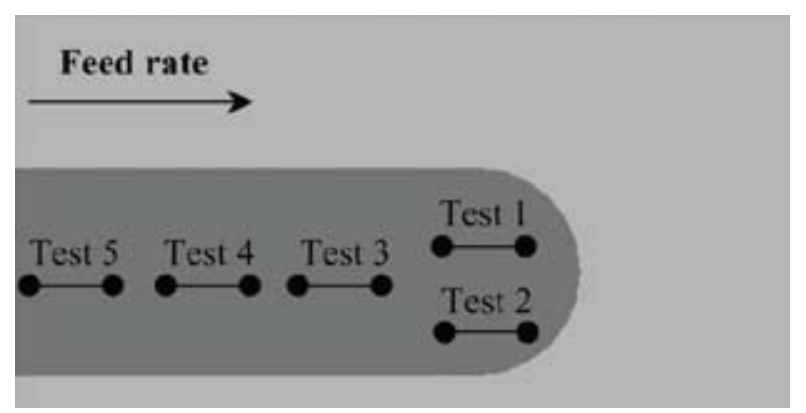

Figure 3. Diagram of measurement that were made over each Milling surface.
The set up for measurement of Delamination using pulsed Thermography was done as shown in the Fig 4.

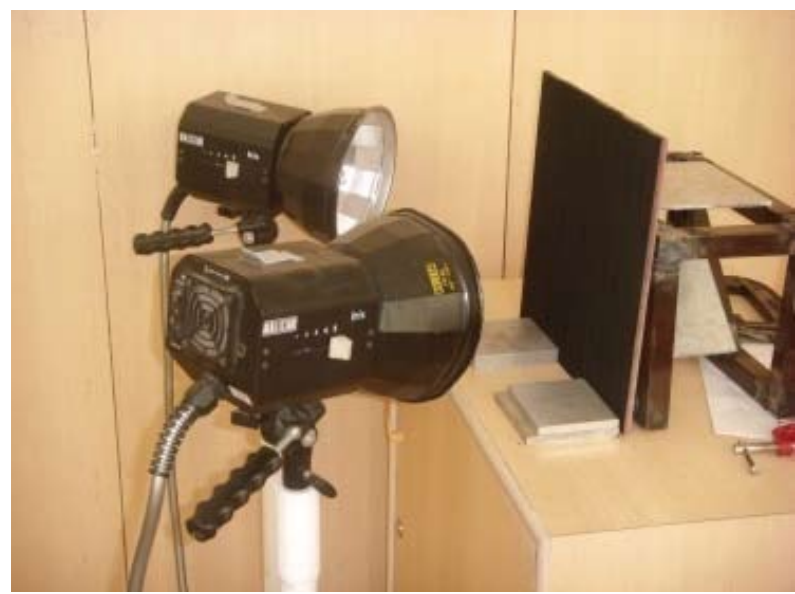

Figure 4. Infrared Thermography setup for the measurement of delamination occurred during milling.

The computation of the delamination was done by the measurement of the Maximum width of damage (Wmax) suffered by the material, the damage normally assigned by delamination factor (Fd) was determined. This factor is defined as the quotient between the maximum width of damage $\left(\mathrm{W}_{\max }\right)$, and the width of cut $(\mathrm{W})$.

The value of delamination factor $(\mathrm{Fd})$ can be obtained by the following equation:

$F d=\frac{\mathrm{W}_{\max }}{\mathrm{W}}$

$\mathrm{W}_{\max }$ being the maximum width of damage in $\mu \mathrm{m}$ and $\mathrm{W}$ the width of cut in $\mu \mathrm{m}$

The maximum width of damage in $\mu \mathrm{m}$ was obtained by the images from the Altair software as shown in the fig 5, the details of which are given below:

Dimensions of each IR image : 164 X 58 pixels

Horizontal Dimension as measured from

IR image

$: 2.54 \mathrm{~mm}$

Length of each image

:164 pixels

1 pixel

$=1.54 \mathrm{~mm}$

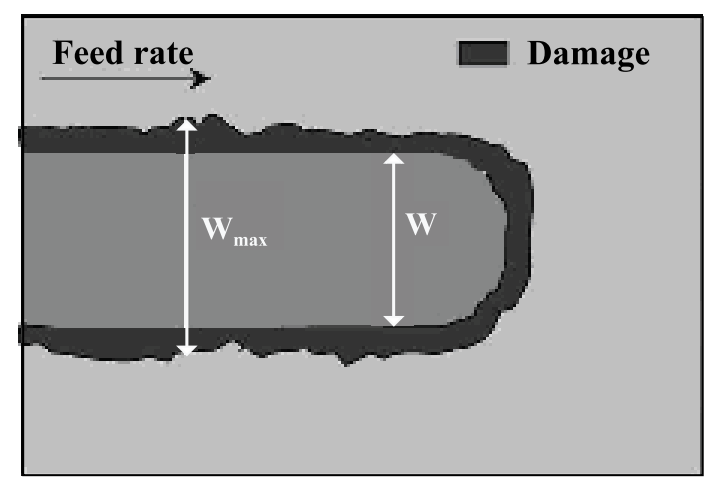

Figure 5. Scheme of delamination factor with IR Thermography. 


\subsection{Taguchi Method}

Taguchi's method has been used widely in engineering analysis. These techniques consist of a plan of experiments with the objective of acquiring data in a controlled way, executing these experiments, in order to obtain information about the behavior of a given process.

For the elaboration of experimental plan we used the method of Taguchi for three factors with three levels. The array chosen was the L9 $\left(3^{4}\right)$ which have nine rows corresponding to the number of tests. Table 1 indicates the factors to be studied and the assignment of the corresponding levels.

Table 1. Factors to be studied and the Assignment of the Levels to the Factors

\begin{tabular}{cccc}
\hline \multirow{2}{*}{ Level } & \multicolumn{3}{c}{ Factors } \\
\cline { 2 - 4 } & $\begin{array}{c}\text { Cutting } \\
\text { velocity } \\
\text { V (m/min) }\end{array}$ & $\begin{array}{c}\text { Feed rate } \\
\mathbf{f}(\mathbf{m m} / \mathbf{m i n})\end{array}$ & $\begin{array}{c}\text { Depth of cut } \\
\mathbf{d}(\mathbf{m m})\end{array}$ \\
\hline 1 & 24 & 300 & 0.5 \\
2 & 48 & 600 & 1.5 \\
3 & 72 & 900 & 2.5 \\
\hline
\end{tabular}

\section{Results and Discussion}

The results of the milling tests allowed the evaluation of the GFRP composite material manufacture by hand-lay up, using three different carbide K10 end mills. The Machinability was evaluated by surface roughness $(\mathrm{Ra})$.

\subsection{Influence of the cutting parameters on the surface roughness based on $\mathrm{S} / \mathrm{N}$ Ratio}

Table 2 shows the results of the surface roughness (Ra) as a function of the cutting parameters, for the solid carbide, tipped carbide and Ti-Namite coated carbide tool. Table 4-6 illustrates the results of Taguchi analysis $(\mathrm{S} / \mathrm{N}$ ratio) of the surface roughness in the GFRP laminate for the three different carbide end mills using the approach of smaller is better.

Table 2. Values of $\mathrm{Ra}$ as a function of the cutting parameters

\begin{tabular}{ccccccc}
\hline & & & & \multicolumn{3}{c}{ Ra $(\mu \mathbf{m})$} \\
\cline { 5 - 7 } Test & $\begin{array}{c}\mathbf{V} \\
(\mathbf{m} / \mathbf{m i n})\end{array}$ & $\begin{array}{c}\mathbf{f} \\
(\mathbf{m m} / \mathbf{m i n})\end{array}$ & $\begin{array}{c}\mathbf{d} \\
(\mathbf{m m})\end{array}$ & $\begin{array}{c}\text { Ti- } \\
\text { Namite } \\
\text { Coated } \\
\text { carbide }\end{array}$ & $\begin{array}{c}\text { Solid } \\
\text { Carbide }\end{array}$ & $\begin{array}{c}\text { Tipped } \\
\text { Carbide }\end{array}$ \\
\hline 1 & 24 & 300 & 0.5 & 4.77 & 8.87 & 4.07 \\
2 & 24 & 600 & 1.5 & 9.03 & 9.21 & 4.72 \\
3 & 24 & 900 & 2.5 & 6.84 & 9.23 & 4.32 \\
4 & 48 & 300 & 1.5 & 6.94 & 5.27 & 3.30 \\
5 & 48 & 600 & 2.5 & 4.61 & 4.48 & 4.49 \\
6 & 48 & 900 & 0.5 & 5.64 & 4.63 & 5.91 \\
7 & 72 & 300 & 2.5 & 3.59 & 3.47 & 5.47 \\
8 & 72 & 600 & 0.5 & 3.18 & 6.15 & 4.74 \\
9 & 72 & 900 & 1.5 & 9.75 & 4.92 & 4.17 \\
\hline
\end{tabular}

From table 3 it can be seen that the factor depth of cut (DOC) is the most significant and the factor feed is the next significant in the use of Ti-Namite carbide K10 end mill. In table 4 the factor velocity is the most significant and the factor depth of cut is the next significant factor in the use of solid carbide end mill. From table 5 it can be seen that the factor depth of cut is the most significant factor and the factor feed rate is the next significant factor in the use of tipped carbide end mill. From the analysis above, the depth of cut are seen to make the largest contribution to the overall performance.

Table 3. Response of Signal to Noise Ratios for the surface roughness $(\mathrm{Ra})$ of Ti-Namite carbide end mill

\begin{tabular}{cccc}
\hline \multirow{2}{*}{ Level } & \multicolumn{3}{c}{ Factors } \\
\cline { 2 - 4 } & $\mathbf{V}(\mathbf{m} / \mathbf{m i n})$ & $\mathbf{f}(\mathbf{m m} / \mathbf{m i n})$ & DOC $(\mathbf{m m})$ \\
\hline 1 & -16.46 & -13.83 & -12.88 \\
2 & -15.04 & -14.15 & -18.57 \\
3 & -13.64 & -17.17 & -13.69 \\
Delta & 2.82 & 3.34 & 5.69 \\
Rank & 3 & 2 & 1 \\
\hline
\end{tabular}

Table 4. Response of Signal to Noise Ratios for the surface roughness $(\mathrm{Ra})$ of solid carbide end mill

\begin{tabular}{cccc}
\hline \multirow{2}{*}{ Level } & \multicolumn{3}{c}{ Factors } \\
\cline { 2 - 4 } & $\mathbf{V ~ ( \mathbf { m } / \mathbf { m i n } )}$ & $\mathbf{f}(\mathbf{m m} / \mathbf{m i n})$ & DOC $(\mathbf{m m})$ \\
\hline 1 & -19.18 & -14.73 & -16.02 \\
2 & -13.59 & -16.03 & -15.85 \\
3 & -13.47 & -15.48 & -14.38 \\
Delta & 5.71 & 1.30 & 1.64 \\
Rank & 1 & 3 & 2 \\
\hline
\end{tabular}

Table 5. Response of Signal to Noise Ratios for the surface roughness (Ra) of Tipped carbide end mill

\begin{tabular}{cccc}
\hline \multirow{2}{*}{ Level } & \multicolumn{3}{c}{ Factors } \\
\cline { 2 - 4 } & $\mathbf{V}(\mathbf{m} / \mathbf{m i n})$ & $\mathbf{f}(\mathbf{m m} / \mathbf{m i n})$ & DOC $(\mathbf{m m})$ \\
\hline 1 & -12.79 & -12.44 & -13.71 \\
2 & -12.95 & -13.35 & -12.08 \\
3 & -13.56 & -13.51 & -13.50 \\
Delta & 0.77 & 1.07 & 1.63 \\
Rank & 3 & 2 & 1 \\
\hline
\end{tabular}

The value of international dimensional precision (IT) can be obtained by the following empirical equation according to UNI ISO 3963/2:

$\mathrm{IT}=30 \mathrm{Ra}$

Ra being the surface roughness in $\mu \mathrm{m}$. 
Table 6. Values of international dimensional precision (IT) as a function of the cutting parameters

\begin{tabular}{|c|c|c|c|c|c|c|}
\hline \multirow[b]{2}{*}{ Test } & \multirow[b]{2}{*}{$\underset{(m / m i n)}{V}$} & \multirow[b]{2}{*}{$\begin{array}{c}\mathbf{f} \\
(\mathrm{mm} / \mathrm{min})\end{array}$} & \multirow[b]{2}{*}{$\underset{(\mathrm{mm})}{\mathrm{d}}$} & \multicolumn{3}{|c|}{$\begin{array}{c}\text { International dimensional } \\
\text { precision IT }(\mu \mathrm{m})\end{array}$} \\
\hline & & & & $\begin{array}{c}\text { Ti- } \\
\text { Namite } \\
\text { Coated } \\
\text { carbide }\end{array}$ & $\begin{array}{c}\text { Solid } \\
\text { Carbide }\end{array}$ & $\begin{array}{l}\text { Tipped } \\
\text { Carbide }\end{array}$ \\
\hline 1 & 24 & 300 & 0.5 & 143.1 & 266.1 & 122.1 \\
\hline 2 & 24 & 600 & 1.5 & 207.9 & 276.3 & 141.6 \\
\hline 3 & 24 & 900 & 2.5 & 205.2 & 276.9 & 129.6 \\
\hline 4 & 48 & 300 & 1.5 & 208.2 & 158.1 & 99.0 \\
\hline 5 & 48 & 600 & 2.5 & 138.3 & 134.4 & 134.7 \\
\hline 6 & 48 & 900 & 0.5 & 169.2 & 138.9 & 177.3 \\
\hline 7 & 72 & 300 & 2.5 & 107.7 & 104.1 & 164.1 \\
\hline 8 & 72 & 600 & 0.5 & 95.4 & 184.5 & 142.2 \\
\hline 9 & 72 & 900 & 1.5 & 292.5 & 147.6 & 125.1 \\
\hline
\end{tabular}

Table 7 shows the result of the dimensional precision (IT), obtained by Eq.(2), as a function of the cutting parameters.

Table 7. Values of delamination factor $(\mathrm{Fd})$ as a function of the cutting parameters

\begin{tabular}{ccccccc}
\hline & & & \multicolumn{4}{c}{ Delamination factor (Fd) } \\
\cline { 5 - 7 } Test & $\begin{array}{c}\mathbf{V} \\
(\mathbf{m} / \mathbf{m i n})\end{array}$ & $\begin{array}{c}\mathbf{f} \\
(\mathbf{m m} / \mathbf{m i n})\end{array}$ & $\begin{array}{c}\mathbf{d} \\
(\mathbf{m m})\end{array}$ & $\begin{array}{c}\text { Ti- } \\
\text { Namite } \\
\text { Coated } \\
\text { carbide }\end{array}$ & $\begin{array}{c}\text { Solid } \\
\text { Carbide }\end{array}$ & $\begin{array}{c}\text { Tipped } \\
\text { Carbide }\end{array}$ \\
\hline 1 & 24 & 300 & 0.5 & 1.308 & 1.462 & 1.154 \\
2 & 24 & 600 & 1.5 & 1.462 & 1.308 & 1.308 \\
3 & 24 & 900 & 2.5 & 1.462 & 1.462 & 1.462 \\
4 & 48 & 300 & 1.5 & 1.308 & 1.154 & 1.308 \\
5 & 48 & 600 & 2.5 & 1.308 & 1.308 & 1.462 \\
6 & 48 & 900 & 0.5 & 1.462 & 1.462 & 1.462 \\
7 & 72 & 300 & 2.5 & 1.462 & 1.770 & 1.462 \\
8 & 72 & 600 & 0.5 & 1.154 & 1.924 & 1.462 \\
9 & 72 & 900 & 1.5 & 1.462 & 1.924 & 1.154 \\
\hline
\end{tabular}

\subsection{Influence of the cutting parameters on the delamination factor based on S/N Ratio}

Table 7 shows the results of the delamination factor $(\mathrm{Fd})$ as a function of the cutting parameters, for the solid carbide, tipped carbide and Ti-Namite coated carbide tool. Table 8-10 illustrates the results of Taguchi analysis( $\mathrm{S} / \mathrm{N}$ ration) of the delamination factor in the GFRP laminate for the three different carbide end mills using the approach of smaller is better.

From table 8 it can be seen that the factor feed rate is the most significant and the factor depth of cut (DOC) is the next significant in the use of Ti-Namite carbide K10 end mill. In table 9 the factor velocity is the most significant and the factor depth of cut is the next significant factor in the use of solid carbide end mill. From table 10 it can be seen that the factor depth of cut is the most significant factor and the factor feed rate and velocity are equally significant factor in the use of tipped carbide end mill. From the analysis above, the depth of cut are seen to make the largest contribution to the overall performance.

Table 8. Response of Signal to Noise Ratios for the delamination factor (Fd) of Ti-Namite carbide end mill.

\begin{tabular}{cccc}
\hline \multirow{2}{*}{ Level } & \multicolumn{3}{c}{ Factors } \\
\cline { 2 - 4 } & $\mathbf{V}(\mathbf{m} / \mathbf{m i n})$ & $\mathbf{f}(\mathbf{m m} / \mathbf{m i n})$ & DOC $(\mathbf{m m})$ \\
\hline 1 & -2.977 & -2.654 & -2.292 \\
2 & -2.654 & -2.292 & -2.977 \\
3 & -2.614 & -3.299 & -2.977 \\
Delta & 0.363 & 1.007 & 0.685 \\
Rank & 3 & 1 & 2 \\
\hline
\end{tabular}

Table 9. Response of Signal to Noise Ratios for the delamination factor $(\mathrm{Fd})$ of solid carbide end mill.

\begin{tabular}{cccc}
\hline \multirow{2}{*}{ Level } & \multicolumn{3}{c}{ Factors } \\
\cline { 2 - 4 } & $\mathbf{V ~ ( \mathbf { m } / \mathbf { m i n } )}$ & $\mathbf{f}(\mathbf{m m} / \mathbf{m i n})$ & DOC $(\mathbf{m m})$ \\
\hline 1 & -2.977 & -3.168 & -4.094 \\
2 & -2.292 & -3.449 & -3.087 \\
3 & -5.443 & -4.094 & -3.530 \\
Delta & 3.151 & 0.926 & 1.007 \\
Rank & 1 & 3 & 2 \\
\hline
\end{tabular}

Table 10. Response of Signal to Noise Ratios for the delamination factor $(\mathrm{Fd})$ of Tipped carbide end mill.

\begin{tabular}{cccc}
\hline \multirow{2}{*}{ Level } & \multicolumn{3}{c}{ Factors } \\
\cline { 2 - 4 } & $\mathbf{V}(\mathbf{m} / \mathbf{m i n})$ & $\mathbf{f}(\mathbf{m m} / \mathbf{m i n})$ & DOC $(\mathbf{m m})$ \\
\hline 1 & -2.292 & -2.292 & -2.614 \\
2 & -2.977 & -2.977 & -1.969 \\
3 & -2.614 & -2.614 & -3.299 \\
Delta & 0.685 & 0.685 & 1.329 \\
Rank & 2.5 & 2.5 & 1 \\
\hline
\end{tabular}

\subsection{Influence of the cutting parameters on the surface roughness -ANOVA}

Table 2 shows the results of the surface roughness ( $\mathrm{Ra}$ ) as a function of the cutting parameters, for the solid carbide, tipped carbide and Ti-Namite coated carbide tool.

Fig. 6, 7 and 8 shows the main effects plots of the surface roughness $(\mathrm{Ra})$ with cutting velocity, Feed rate and depth of cut for Ti-Namite coated carbide end mill, solid carbide and tipped carbide tools.

From Fig. 6 it can be realized that Ra values decreases with velocity for Ti-Namite carbide and solid carbide. 


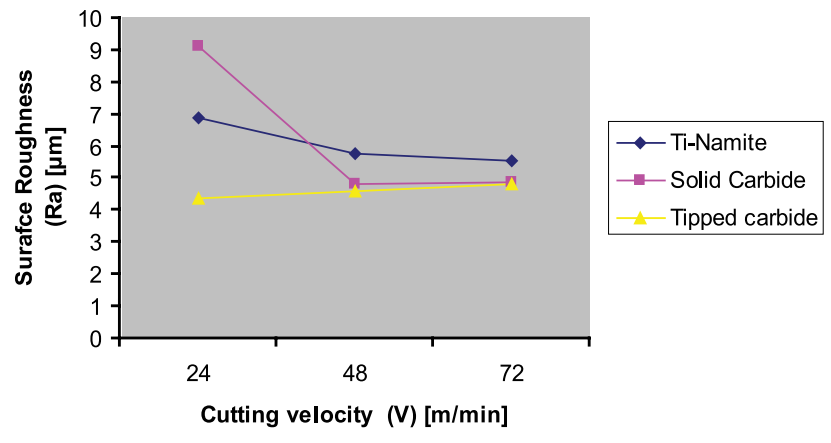

Figure 6. Variation of Surface roughness with cutting velocity for Ti-Namite coated carbide end mill, Solid carbide end mill and tipped carbide end mill.

From Fig. 7 it can be realized that Ra values increases with feed for Ti-Namite carbide, solid carbide and tipped carbide end mills.

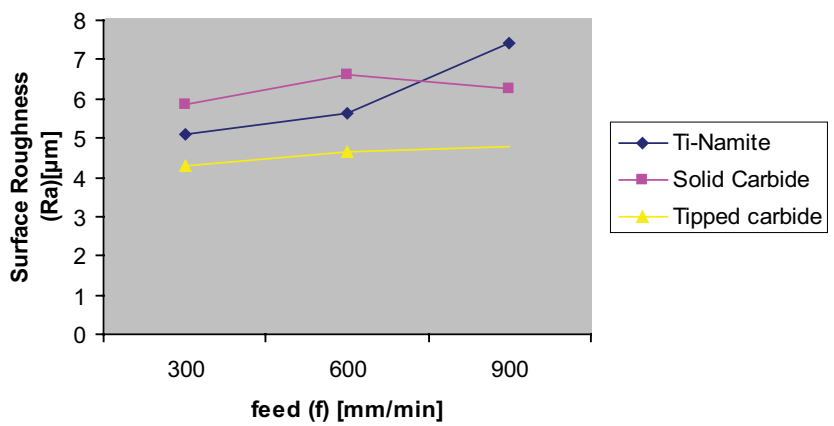

Figure 7. Variation of Surface roughness with feed rate for Ti-Namite coated carbide end mill, Solid carbide end mill and tipped carbide end mill.

From Fig. 8 it can be realized that Ra values decreases with Depth of cut for solid carbide and tipped carbide, whereas the Ra value increases with depth of cut for Ti-Namite coated carbide. It can also be observed that the Ti-Namite carbide provides a better surface finish than the Solid carbide and tipped carbide.

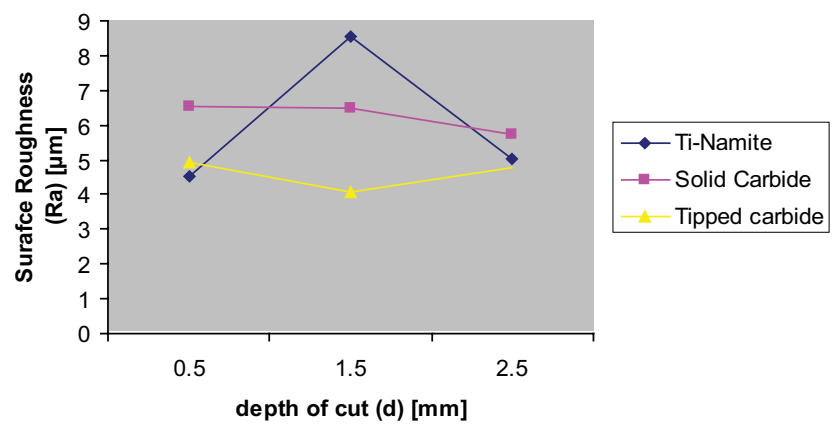

Figure 8. Variation of Surface roughness with depth of cut for Ti-Namite coated carbide end mill, Solid carbide end mill and tipped carbide end mill.

From table 11, it can be realized that the depth of cut factor $(\mathrm{P}=69.4 \%)$ have statistical and physical significance on the surface roughness $(\mathrm{Ra})$ obtained for Ti-Namite coated carbide end mill. The error associated to the table ANOVA for Ra was approximately $1.8 \%$.

Also from table 11, it can be inferred that the cutting velocity factor $(\mathrm{P}=90.1 \%)$, have statistical and physical significance on the obtained surface roughness (Ra) for solid carbide end mill. The error associated to the table ANOVA for Ra was approximately $4.9 \%$

Equally from table 11, it is found that the factor Cutting velocity, Feed rate and depth of cut does not present statistical significance and also the error associated with it is high.

Table 11. Table ANOVA for the Surface roughness (Ra) for the three K10 end mills

\begin{tabular}{ccccccc}
\hline $\begin{array}{l}\text { Source of } \\
\text { Variance }\end{array}$ & d.f & SDQ & $\begin{array}{c}\text { Vari- } \\
\text { ance }\end{array}$ & Test F & F $\boldsymbol{\alpha}=\mathbf{5 \%}$ & $\mathbf{P}$ \\
\hline Ti-Namite Coated Carbide end mill & & & \\
\hline V(m/min) & 2 & 3.258 & 1.629 & 4.10 & 19.0 & 7.8 \\
$\mathrm{f}(\mathrm{mm} / \mathrm{min})$ & 2 & 8.848 & 4.422 & 11.12 & 19.0 & 21.0 \\
DOC(mm) & 2 & 29.256 & 14.628 & 36.80 & 19.0 & 69.4 \\
Error & 2 & 0.795 & 0.398 & - & - & 1.8 \\
Total & 8 & 42.157 & - & - & - & 100 \\
\hline Solid carbide end mill & & & & \\
\hline V(m/min) & 2 & 36.698 & 18.349 & 19.12 & 19.0 & 90.1 \\
f(mm/min) & 2 & 0.830 & 0.415 & 0.42 & 19.0 & 2.0 \\
DOC(mm) & 2 & 1.232 & 0.616 & 0.63 & 19.0 & 3.0 \\
Error & 2 & 1.971 & 0.986 & - & - & 4.9 \\
Total & 8 & 40.731 & - & - & - & 100 \\
\hline Tipped Carbide & & & & & \\
\hline V(m/min) & 2 & 0.269 & 0.135 & 0.10 & 19.0 & 5.7 \\
f(mm/min) & 2 & 0.430 & 0.215 & 0.15 & 19.0 & 9.1 \\
DOC(mm) & 2 & 1.218 & 0.609 & 0.43 & 19.0 & 25.7 \\
Error & 2 & 2.831 & 2.831 & 1.416 & - & 59.5 \\
Total & 8 & 4.748 & - & - & - & 100 \\
\hline
\end{tabular}

\subsection{Influence of the cutting parameters on the delamination factor-ANOVA}

Fig. 9, 10 and 11 shows the main effects plots of the delamination factor (Fd) with cutting velocity, Feed rate and depth of cut for Ti-Namite coated carbide end mill, solid carbide and tipped carbide tools.

From Fig. 9 it can be realized that Fd values decreases with velocity for Ti-Namite carbide and solid carbide, whereas Fd value increases with velocity for tipped carbide.

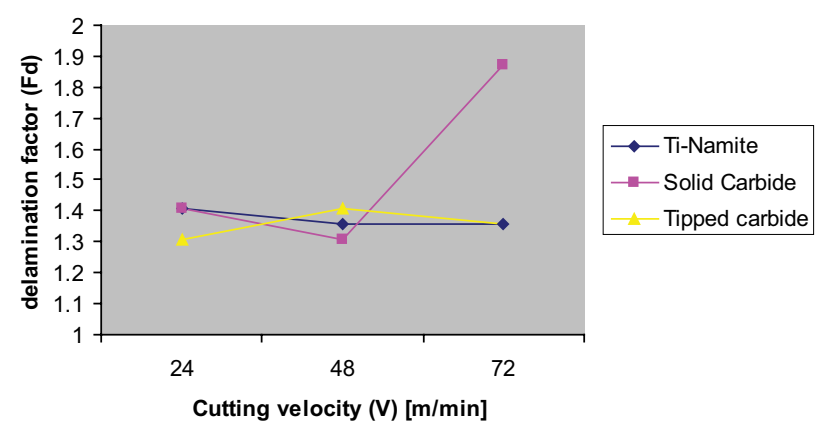

Figure 9. Variation of delamination factor with cutting velocity for Ti-Namite coated carbide end mill, Solid carbide end mill and tipped carbide end mill.

From Fig. 10 it can be realized that Fd values decreases with 
feed for Ti-Namite carbide, whereas Fd value increases with feed for solid carbide and tipped carbide end mills.

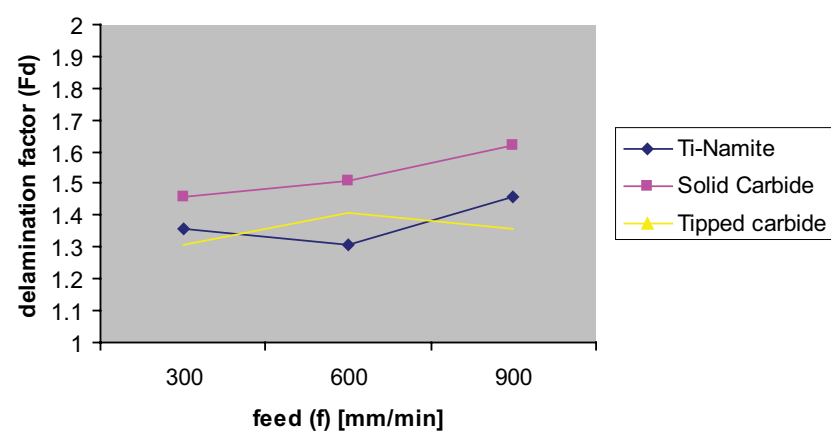

Figure 10. Variation of delamination factor with feed rate for Ti-Namite coated carbide end mill, Solid carbide end mill and tipped carbide end mill.

From Fig. 11 it can be realized that Fd values decreases with Depth of cut for solid carbide and tipped carbide, whereas the $\mathrm{Fd}$ value increases with depth of cut for Ti-Namite coated carbide.

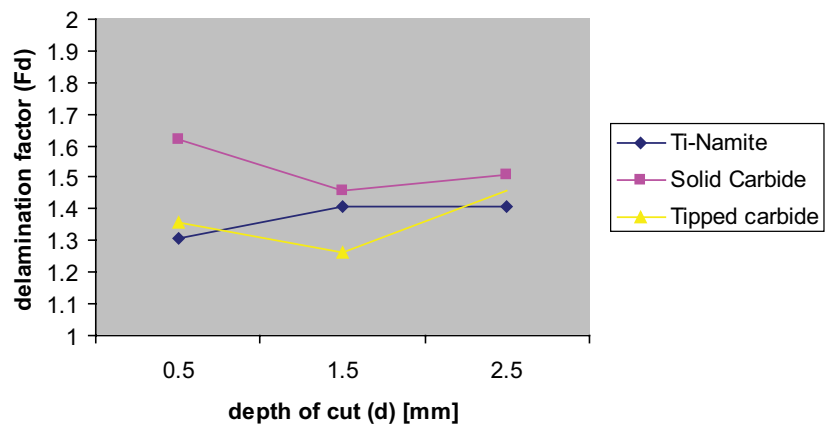

Figure 11. Variation of delamination factor with depth of cut for Ti-Namite coated carbide end mill, Solid end mill and tipped carbide end mill.

Table 12. Table ANOVA for the delamination factor $(\mathrm{Fd})$ for the three K10 end mills

\begin{tabular}{|c|c|c|c|c|c|c|}
\hline $\begin{array}{l}\text { Source of } \\
\text { Variance }\end{array}$ & d.f & SDQ & Variance & Test F & $\begin{array}{l}\mathbf{F} \alpha= \\
5 \%\end{array}$ & $\mathbf{P}$ \\
\hline \multicolumn{7}{|c|}{ Ti-Namite Coated Carbide end mill } \\
\hline $\mathrm{V}(\mathrm{m} / \mathrm{min})$ & 2 & $5.30 \mathrm{E}-03$ & $2.64 \mathrm{E}-03$ & 0.14 & 19.0 & $\overline{5.3}$ \\
\hline $\mathrm{f}(\mathrm{mm} / \mathrm{min})$ & 2 & $3.68 \mathrm{E}-02$ & $1.85 \mathrm{E}-02$ & 1.00 & 19.0 & 36.8 \\
\hline $\mathrm{DOC}(\mathrm{mm})$ & 2 & $2.10 \mathrm{E}-02$ & $1.05 \mathrm{E}-02$ & 0.57 & 19.0 & 21.0 \\
\hline Error & 2 & $3.68 \mathrm{E}-02$ & $1.85 \mathrm{E}-02$ & - & - & 36.9 \\
\hline Total & 8 & $1.00 \mathrm{E}-01$ & - & - & - & 100 \\
\hline \multicolumn{7}{|c|}{ Solid carbide end mill } \\
\hline $\mathrm{V}(\mathrm{m} / \mathrm{min})$ & 2 & $5.43 \mathrm{E}-01$ & $2.71 \mathrm{E}-01$ & 103.00 & 19.0 & $\overline{87.3}$ \\
\hline $\mathrm{f}(\mathrm{mm} / \mathrm{min})$ & 2 & $3.69 \mathrm{E}-02$ & $1.85 \mathrm{E}-02$ & 7.00 & 19.0 & 5.9 \\
\hline $\mathrm{DOC}(\mathrm{mm})$ & 2 & 3.69E-02 & $1.85 \mathrm{E}-02$ & 7.00 & 19.0 & 5.9 \\
\hline Error & 2 & $5.27 \mathrm{E}-03$ & $2.64 \mathrm{E}-03$ & - & - & 0.9 \\
\hline Total & 8 & $6.22 \mathrm{E}-01$ & - & - & - & 100 \\
\hline \multicolumn{7}{|c|}{ Tipped Carbide } \\
\hline $\mathrm{V}(\mathrm{m} / \mathrm{min})$ & 2 & $1.58 \mathrm{E}-02$ & $7.91 \mathrm{E}-03$ & 0.33 & 19.0 & 11.1 \\
\hline $\mathrm{f}(\mathrm{mm} / \mathrm{min})$ & 2 & $1.58 \mathrm{E}-02$ & 7.91E-03 & 0.33 & 19.0 & 11.1 \\
\hline $\mathrm{DOC}(\mathrm{mm})$ & 2 & $6.32 \mathrm{E}-02$ & $3.16 \mathrm{E}-02$ & 1.33 & 19.0 & 44.5 \\
\hline Error & 2 & 4.74E-02 & $2.37 \mathrm{E}-02$ & - & - & 33.3 \\
\hline Total & 8 & $1.42 \mathrm{E}-01$ & - & - & - & 100 \\
\hline
\end{tabular}

From table 12, it can be realized that the factors Cutting velocity, Feed rate and depth of cut does not have a statistical and physical significance on the delamination factor Fd for Ti-Namite coated carbide end mill. The error associated to the table ANOVA for Fd was also high.

Also from table 12, it can be inferred that the cutting velocity factor $(\mathrm{P}=87.3 \%)$, have statistical and physical significance on the obtained delamination factor for solid carbide end mill. The error associated to the table ANOVA for Fd was approximately $0.9 \%$

Equally from table 12, it is found that the factor Cutting velocity, Feed rate and depth of cut does not present statistical significance for tipped carbide end mill and also the error associated to the table ANOVA for Fd was high.

\subsection{Multiple regression analysis (MRA)}

The correlation factors (cutting velocity, feed rate and depth of cut) and surface roughness and delamination factor (Fd), for three end mills on the GFRP composite material were obtained by multiple regression with a sample size (n) of 9.The equations obtained for the three end mills were as follows:

\section{Ti-Namite coated carbide end mill:}

$\mathrm{Ra}=3.74+8.8 \times 10^{-3} \mathrm{~V}+8.7 \times 10^{-4} \mathrm{f}-7.3 \times 10^{-2} \mathrm{~d}$

$F d=1.18+1.07 \times 10^{-3} \mathrm{~V}+8.6 \times 10^{-5} \mathrm{f}+5.13 \times 10^{-2} \mathrm{~d}$

\section{Solid Carbide end mill:}

$\mathrm{Ra}=10.7-8.87 \times 10^{-2} \mathrm{~V}+0.0006 .5 \times 10^{-4} \mathrm{f}-4.12 \times 10^{-3} \mathrm{~d}$

$F d=0.991+9.63 \times 10^{-3} \mathrm{~V}+2.57 \times 10^{-4} \mathrm{f}-5.13 \times 10^{-2} \mathrm{~d}$

\section{Tipped carbide end mill:}

$\mathrm{Ra}=3.74+8.8 \times 10^{-3} \mathrm{~V}+8.7 \times 10^{-4} \mathrm{f}-7.3 \times 10^{-2} \mathrm{~d}$

$F d=1.18+1.07 \times 10^{-3} \mathrm{~V}+8.6 \times 10^{-5} \mathrm{f}+5.13 \times 10^{-2} \mathrm{~d}$

$\mathrm{V}$ being the cutting velocity in $\mathrm{m} / \mathrm{min}$, f being the feed rate in $\mathrm{mm} /$ $\mathrm{min}$, and $\mathrm{d}$ being depth of cut in $\mathrm{mm}$.

Confirmation Test: The above equations were validated using a confirmation test and the error was found to be within $5 \%$ in all the cases. Hence, Eqs. (3)-(8) are demonstrated as a feasible and effective way for the evaluation of Milling induced delamination factor and Surface Roughness in case of GFRP.

\section{Conclusion}

An experimental approach to the evaluation of delamination caused by various cemented carbide K10 end mill using design of experiments was proposed in this study. The results are summarized as follows:

- For tipped carbide, it was possible to obtain surfaces between 3 and $5 \mu \mathrm{m}$ of surface roughness $\left(\mathrm{R}_{\mathrm{a}}\right)$, as function of cutting parameters used which is suitable for most of the industrial applications. 
- For Ti-Namite and Solid carbide the value of surfaces obtained was between 3 and $9 \mu \mathrm{m}$ of surface roughness $\left(\mathrm{R}_{\mathrm{a}}\right)$, as function of cutting parameters used, which is higher when compared to tipped carbide tool necessitating the use of optimal parameter values to obtain the same roughness value. For eg. In case of Ti-Namite tool the optimal value is highest cutting speed ( $\mathrm{V}=72 \mathrm{~m} / \mathrm{min})$, the lowest depth of cut $(\mathrm{d}=0.5 \mathrm{~mm})$ and feed rate of $(\mathrm{F}=600 \mathrm{~mm} / \mathrm{min})$ and in case of Solid Carbide highest cutting speed ( $\mathrm{V}=72 \mathrm{~m} / \mathrm{min})$, the highest depth of cut $(\mathrm{d}=2.5 \mathrm{~mm})$ and lowest feed rate of ( $\mathrm{F}=300 \mathrm{~mm} / \mathrm{min}$ ) lead to optimal value.
- Ti-Namite coated carbide end mill and tipped carbide end mill produces less damage on GFRP composite material than the solid carbide end mill i.e. the delamination factor is smaller.

- Ti-Namite coated carbide tool can be used to obtain a better dimensional precision $(95.4 \mu \mathrm{m})$

- The depth of cut factor is seen to make the largest contribution to the overall performance in both the cases.

- The equations (3)-(8) obtained can be effectively used to evaluate the milling induced delamination factors and surface roughness obtained.

\section{References}

1. D. Hull, T. W. Clyne, An introduction to composite materials, Second Edition, Cambridge University Press. (1996).

2. K. L. Edwards, An Overview of the technology of Fiber-reinforced plastics for design purposes, Journal of Materials and Design. Vol 49, pp. 1-10. (1998).

3. P. S. Sreejith, R. Krishnamurthy, S. K. Malhota, K. Narayanasamy, Evaluation of PCD tool performance during machining of carbon/Phenolics ablative composites. Journal of Material Processing Technology, 104: 53-58. (2000)

4. J. R. Ferreira, N. L. Coppini, G. W. A. Miranda, Machining optimization in carbon fibre reinforced composite materials. Journal of Material Processing Technology, 92-93:135-140. (1999)

5. M. Ramulu, C. W. Wern, J. L. Garbini, Effect of the direction on surface roughness measurement of machined graphite/epoxy composite, Composite Manufacturing. 4 (1), pp. 39-51. (1993)

6. E. Erisken, Influence from production parameters on the surface roughness of a machine short fibber reinforced thermoplastic. International.
Journal of Machine Tools and Manufacturing. 39:1611-1618. (1999).

7. G. C. Everstine, T. G. Rogers, A theory of machining of reinforced materials, Journal of Composite Materials. 5:94-106. (1971).

8. A. Koplev, A. Lystrup, T. Vorm, The cutting process of composites, Composites, 14 (4), pp. 371-376. (1983).

9. T. Kaneeda, CFRP Cutting mechanism, in Proceeding of the 16 th North American Manufacturing Research Conference, pp. 216-221. (1989)

10. H. Y. Puw, H. Hocheng, Anisotropic chip formation models of cutting of FRP, in: Proceedings of ASME Symposium on Material Removal and Surface Modification Issues in Machining Processes, New York, (1995).

11. G. Santhanakrishman, R. Krishnamurthy, S. K. Malhota, Machinability characteristics of fibre reinforced plastics composites, Journal of. Mechanical Working Technology. 17: 195-204.(1988).

12. J. Paulo Davim, Pedro Reis. Damage and dimensional precision on milling carbon fibber-reinforced plastics using design experiments, Journal of Material Processing Technology. 160: 160-167. (2005). 